Article

\title{
Improving the Reinforcement of Polyolefin Fiber Reinforced Concrete for Infrastructure Applications
}

\author{
Marcos G. Alberti, Alejandro Enfedaque and Jaime C. Gálvez * \\ Departamento de Ingeniería Civil: Construcción, E.T.S de Ingenieros de Caminos, Canales y Puertos, \\ Universidad Politécnica de Madrid, C/Profesor Aranguren, s/n, Madrid 28040, Spain; \\ E-Mails: mgalberti@caminos.upm.es (M.G.A.); alejandro.enfedaque@upm.es (A.E.) \\ * Author to whom correspondence should be addressed; E-Mail: jaime.galvez@upm.es; \\ Tel.: +34-913-365-350.
}

Academic Editor: Mahmoud Reda Taha

Received: 19 October 2015 / Accepted: 16 November 2015 / Published: 26 November 2015

\begin{abstract}
The increase in the use of polyolefin fiber-reinforced concrete (PFRC) is in contrast to the limited amount of published research about its fracture behavior. This study assesses the main mechanical and fracture properties of PFRC by using conventional and self-compacting concrete with various dosages. The results highlight the significant performance of PFRC and revealed that improving its residual strength for small deformations would enhance its use for structural purposes. For that matter, a combination of polyolefin and steel-hooked fibers was used, improving the results and showing synergies between the two types of fibers that could be exploited for infrastructure applications. The significance of this research is, in addition to the characterization of PFRC, the optimum selection and definition of the proportions and characteristics of the types of fibers chosen for the combination. The results proved that, by combining hooked-steel fibers and macro-polyolefin fibers, it is possible to preserve the high-performance fresh properties and obtain a reliable behavior with synergies in the fracture results. The latter provides an efficient use of the materials, as well as a better mechanical behavior in both service and failure states.
\end{abstract}

Keywords: fiber reinforced concrete; polyolefin fibers; steel fibers 


\section{Introduction}

With steel-bar reinforced concrete (RC) having become the par excellence solution in structures in the last century, the possibility of partial or even total substitution of steel-bars by steel fibers would not only allow the cost of a structure to be reduced but also provide certain other improved properties. Once such substitution has been accepted as viable, it will boost industrial development and research on fibers. Hence, new fiber types, with various shapes and constituent materials have emerged [1-3].

The production of steel fiber-reinforced concrete (SFRC) requires the use of materials, admixtures and special operational technology that inevitably increases the cost of the composite material. This is the reason why it is only profitable when enhanced structural properties are required. Some applications, such as pavements and tunneling, often need special requirements that can be achieved by using SFRC (although it has also been employed to meet other structural demands) [4,5]. As SFRC has become more popular in building and civil construction, some constitutive models, design approaches and tests have been developed [6-12]. Hence, the challenges of FRC are now based on the best exploitation of the materials and the optimization of the fibers and matrices in order to produce the most suitable composite material for a specific purpose [13].

Not only the good performance of steel combined with concrete, but also its drawbacks have been widely reported. Some such drawbacks vary from corrosion to high purchase, storage and handling costs. The durability of SFRC has concerned not only engineers but also industry in general. In response to this, the evolution of the plastic industry has allowed chemically stable fibers with improved mechanical properties to be produced [14]. Recently, efforts made in the plastic industry have focused on achieving a new generation of polyolefin based synthetic macro-fibers that are not only inert in an alkaline environment but also offer structural benefits [15]. Such macro-plastic fibers decrease the workability of the fresh concrete to a lesser extent when compared with SF and have no obvious effect on the compressive strength, tensile strength and modulus of elasticity, all of which are dominated by the concrete matrix properties [16]. Hence, the main benefit of using polyolefin fiber-reinforced concrete (PFRC) lies in the excellent post-cracking behavior which, together with cost and environmental benefits, makes it an attractive alternative to conventional steel reinforcement in the construction industry. Plastic fibers can significantly reduce the overall cost of the material and permit the corrosion problems that appear with SF to be avoided. Moreover, some reductions in the carbon footprint, when compared with that of producing steel, have also been reported [17]. In summary, the use of macro-plastic fibers to reinforce concrete instead of use of steel mesh and steel fibers has become appealing to scientists, the concrete-related industries with polyolefin-based fibers being the most common. Therefore, published research has reported that polyolefin-based macro-structural fibers are especially well-suited for infrastructure applications such as the construction of pavements, light precast elements and tunnel linings [18].

However, there is limited published research into a fracture behavior that allows a more reliable use of PFRC in infrastructure applications. It is worth noting that the residual load-bearing capacity is measured by fracture tests. That is to say, the definition of a structural fiber depends on the fracture behavior. As PFRC not only has considerable residual tensile strengths but also meets the requirements of the standards; the contribution of its fibers may be considered in structural design [19]. Even though extended research is still required for a better comprehension of the potential of PFRC, promising results 
obtained from examination of PFRC have been published [16,20-22] and structural applications reported [14,23]. These references both show the possibilities of polyolefin-based macro-fibers as the only reinforcement of concrete and sustain the need of deeper research for a better comprehension of the fracture behavior of PFRC.

This paper supplies significant experimental results that permit PFRC to be considered for total or partial substitution of a steel bar. In addition, it helps to localize the respective weak points and proposes a combination of fibers that are proven to have synergistic effects. In summary, PFRC is shown to have considerable residual tensile strengths and to meet the requirements of the standards in considering the contribution of the fibers in structural design [19].

This research is of direct significance as regards the characterization of PFRC in a fresh and hardened state and, more specifically, the respective fracture properties and residual capacities. However, the selection of the optimum fiber cocktail is significant after having proved the individual contributions. Both such an optimum definition of the proportions and fiber type were carefully chosen. In this sense, the combination of various types of fibers opens a promising field for new research that may provide significant results. Future designing of FRC could be focused on selecting the optimum combination of fiber types and contents. The results of this paper support that future line of research with worthy perspectives.

\section{Concrete Production and Fresh-State Properties}

The component materials included Portland cement type EN 197-1 CEM I 52.5 R-SR 5 and a mineral admixture of limestone used as a micro-aggregate. This limestone powder (LP) had a specific gravity and Blaine surface of, respectively, $2700 \mathrm{~kg} / \mathrm{m}^{3}$ and $400-450 \mathrm{~m}^{2} / \mathrm{kg}$. The calcium carbonate content of the limestone powder was higher than $98 \%$, and less than $0.05 \%$ was retained in a $45-\mu \mathrm{m}$ sieve. A polycarboxylate-based superplasticizer named Sika Viscocrete 5720 with a solid content of $36 \%$ and $1090 \mathrm{~kg} / \mathrm{m}^{3}$ density was employed. The mixtures were made with siliceous aggregates composed of two types of gravel with a size of 4-8 $\mathrm{mm}$ and $4-12 \mathrm{~mm}$ and sand of $0-2 \mathrm{~mm}$. The maximum aggregate size was $12.7 \mathrm{~mm}$. Polyolefin straight fibers with a rough surface and surface treatment were employed with two lengths of 60 and $48 \mathrm{~mm}$. Figure 1 shows the main properties and the geometrical patterns of the fibers.

Polvolefin fibers:

- Available lengths: 48 and $60 \mathrm{~mm}$

- Density: $0.91 \mathrm{gr} / \mathrm{cm}^{3}$

- Equivalent diameter: $0.92 \mathrm{~mm}$

- Tensile strength: $>500 \mathrm{MPa}$

- Elasticity modulus: $>9 \mathrm{GPa}$ (up to 20 in CE Mark)

- Embossed surface
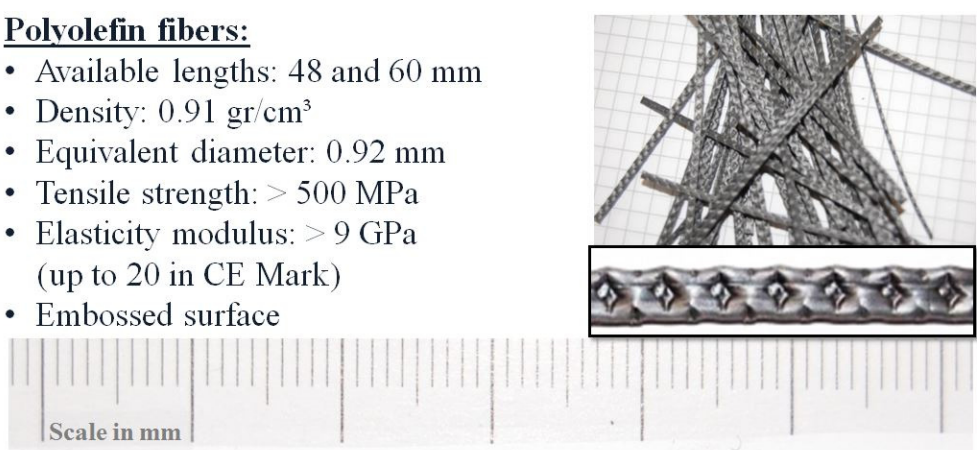

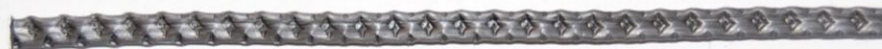

Figure 1. Properties and visual aspect of polyolefin macro-structural fibers. 
The SCC used was prepared and tested to meet the initial requirements of achieving a medium-strength concrete that maintains the self-compactability properties even after the incorporation of fibers. In order to do so, some initial trial mixtures were made to obtain a concrete mix design with as low a cement and admixture content as possible without harming its self-compacting properties when fibers were added. In these trial mixtures, up to $6 \mathrm{~kg} / \mathrm{m}^{3}$ of polyolefin fibers were added to the mix.

For the paste design, the cement required was at least $375 \mathrm{~kg} / \mathrm{m}^{3}$ with $1.25 \%$ of cement weight of Sika Viscocrete-5720 admixture and a water-to-powder ratio of 0.50 . The limestone powder addition remained at $200 \mathrm{~kg} / \mathrm{m}^{3}$, with the paste representing $38 \%$ of the total concrete volume. The proportions of the aggregates were those obtained for the maximum dry packing density, shown in Table 1, and represented $25.5 \%$ of voids. The humidity of the aggregates was corrected before the manufacture of the concretes. The time schedule followed is also shown in Table 1.

Table 1. Proportion of aggregates for dry maximum packing density and mixing procedure.

\begin{tabular}{cc}
\hline Proportion of Aggregates for Dry Maximum Packing Density \\
\hline Aggregate & Value $(\%)$ \\
Gravel & 24 \\
Grit & 16 \\
Sand & 60 \\
Mixing procedure & \\
Process & Duration of mixing process (s) \\
1. Homogenization of aggregates & 60 \\
2. Add 1/3 of fibers and mix & 30 \\
3. Add cement and limestone powder & 30 \\
4. Add $1 / 3$ of fibers and mix & 30 \\
5. Add 75\% of the mixing water and mix & 30 \\
6. Add 1/3 of the fibers and mix & 30 \\
6. Add 25\% of the water with superplasticizer & 240 \\
7. Rest (superplasticizer acting period) & 150 \\
8. Final mix & 120 \\
\hline
\end{tabular}

On the basis of the SCC mix proportioning, a conventional concrete was designed with the challenge of providing analogous fracture energy to the plain concrete. In the fracture tests, after the limit of proportionality was reached, the inelastic processes of plain concrete fracture barely contributed to preventing the collapse of the piece. Nonetheless, analysis should evaluate the energy added by fibers and the structural behavior in the post-cracking region of the curves. In such a case, the fracture energy and residual load-bearing capacity of the plain concrete should be near to each other. The mix proportioning of both types of concrete, SCC and VCC, can be seen in Figure 2.

Through use of SCC and VCC, and with the aim of comparing the behavior with each other, two batches of each mixture with $0,3,4.5,6$ and $10 \mathrm{~kg} / \mathrm{m}^{3}$ of $60 \mathrm{~mm}$-long polyolefin fibers were produced. Hence, five SCC mixtures were named respectively as SCC, PFR-SCC3, PFR-SCC4.5, PFR-SCC6 and PFR-SCC10. The corresponding five mixtures that used VCC were, consequently, named as VCC, PFR-VCC3, PFR-SCC4.5, PFR-SCC6 and PFR-SCC10. One more mixture was manufactured with $10 \mathrm{~kg} / \mathrm{m}^{3}$ that also used a bond improver admixture named Sikatell 250 (see Reference [16]). The latter was named PFR-SCC10M. 
Mix proportioning $\left(\mathrm{kg} / \mathrm{m}^{3}\right)$

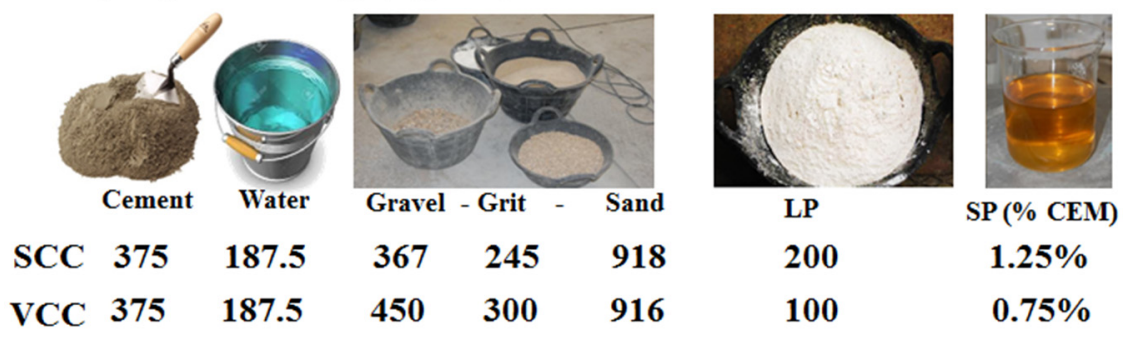

Figure 2. Mix proportions of the plain SCC and VCC used as reference for the mixtures of FRC.

Two mixtures were defined in the initial step with the aim of comparing the results of PRCF with those using $35 \mathrm{~mm}$-long steel-hooked fibers and the SCC formulation. These two mixtures were labeled as SFR-SCC26 and SFR-SCC39. The SF dosages were chosen to coincide in terms of volume fraction with the relative proportions of PFR-SCC3 (0.33\%) and PFR-SCC4.5 (0.49\%). Finally, a hybrid mixture was defined using $26 \mathrm{~kg} / \mathrm{m}^{3}$ of SF, plus $4.5 \mathrm{~kg} / \mathrm{m}^{3}$ of PF added to the SCC formulation. The latter is described in more detail in Section 5 of this paper.

With each type of concrete, two prismatic specimens of $600 \times 150 \times 150 \mathrm{~mm}^{3}$ and nine cylindrical specimens with a height of $300 \mathrm{~mm}$ and diameter of $150 \mathrm{~mm}$ were cast. All the specimens were stored at room temperature for the first $24 \mathrm{~h}$ and then kept in a climatic chamber at $20^{\circ} \mathrm{C}$ and $95 \%$ of relative humidity for 28 days until the age of testing.

Concerning the pouring methods, in the SCC mixes all the specimens were filled in a single pour from one of the sides of the mold. The specimens were subsequently compacted and levelled off by the action of the own weight of the fresh concrete. Those specimens prepared with VCC were compacted for $10 \mathrm{~s}$ by means of a vibratory table and filled following the procedure stated in the standards [10]. That is to say, molds were filled initially in a central portion of approximately $90 \%$ of the height of the specimen and two portions in the half side of it. Then, the mold was topped and levelled while being compacted. Both consolidation processes might affect the distribution and orientation of the fibers and, as a consequence, the fracture behavior of the specimens. These issues and the difference in the procedures can be seen in Figure 3.

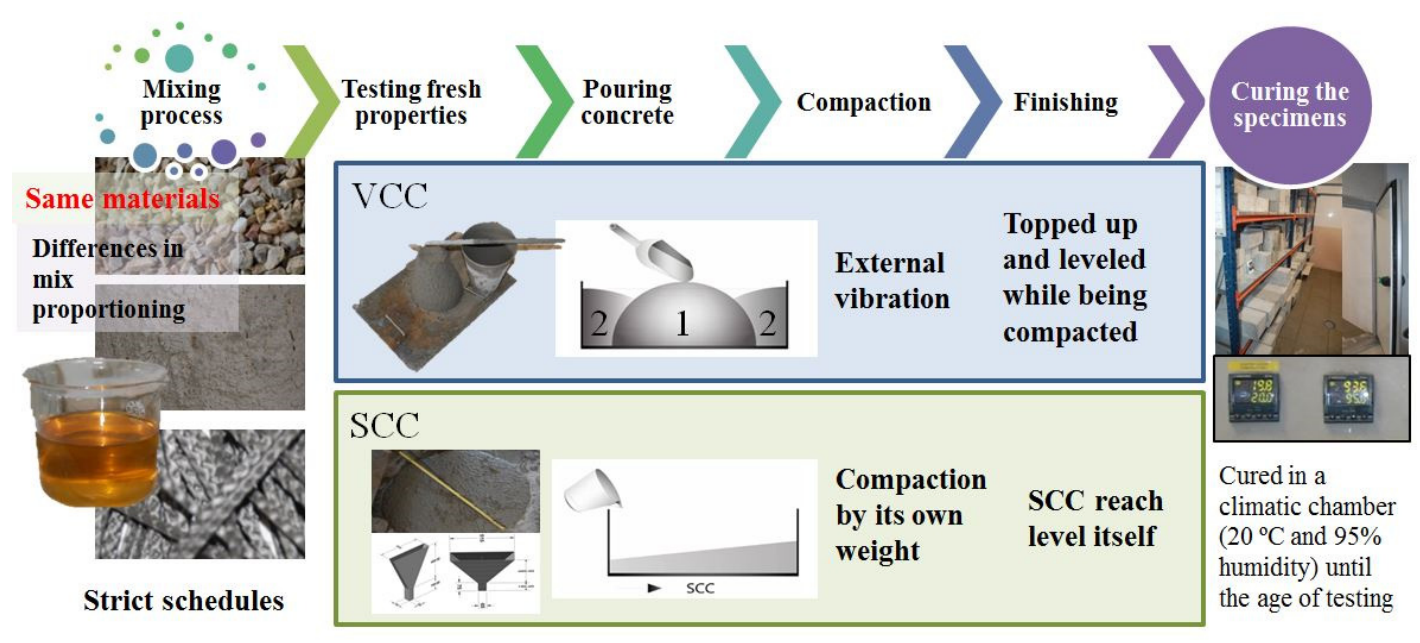

Figure 3. Main processes of SCC and VCC concrete production. 
The fresh-state behavior of SCC mixes, with or without fibers, was assessed by using the slump flow test [24] and the V-funnel test [25]. The results can be seen in Figure 4. The slump flow spread tended to decrease as the amount of fibers increased. In the same sense, the emptying times of the V-funnel test increased proportionally with the fiber dosage. Moreover, there was a subtle influence of fiber length. However, the comparison with the influence of steel-hooked short fibers in mixture SFR-SCC26, which corresponds in volume fraction to the formulation PFR-SCC3, showed the good performance the polyolefin fibers. The latter can be easily observed in Figure 4 and explained by the non-rigid nature of the fibers.

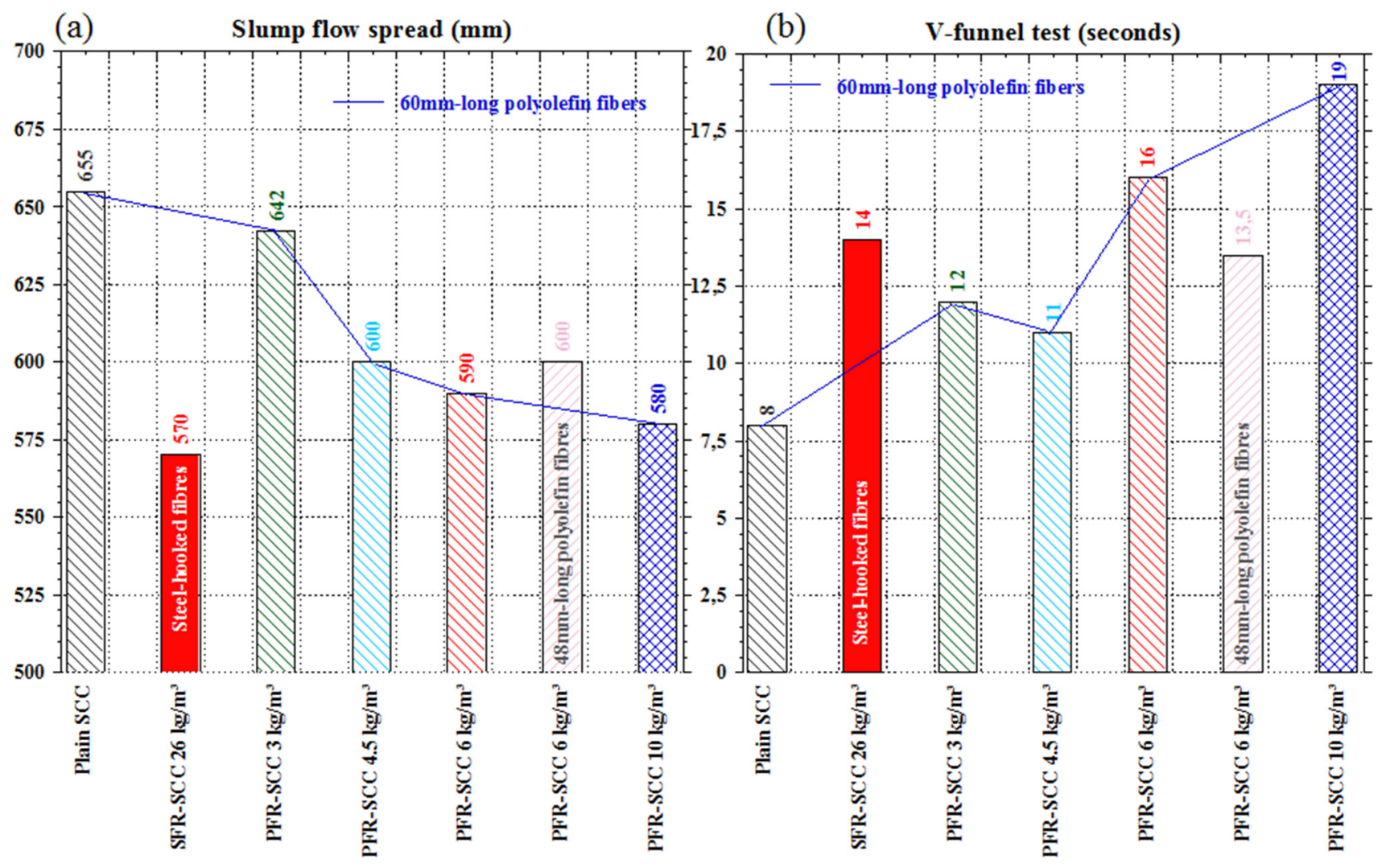

Figure 4. Fresh-state results with several fiber dosages: (a) Slump flow spread diameter; (b) V-funnel emptying times.

Regarding VCC mixes, the fresh-state properties of the concrete were addressed by means of the slump test [26], whether the mixture had fibers or not. In order to obtain similar results in the latter test, the amount of superplasticizer used was increased in the VCC10 formulation from $0.75 \%$ to $0.82 \%$ with respect to cement weight. In consideration of such a modification, the results were around $15 \mathrm{~cm}$ of descent of the mass for all the formulations.

\section{Evaluation of the Mechanical Properties}

The compressive strength, modulus of elasticity and indirect tensile strength tests were performed by using the cylindrical specimens. All these tests were carried out following some of the most employed standards [27-29], using three specimens at 28 days of age. The mean values of all the tests and the coefficient of variation (c.v.) can be seen in Figures 5-7 and Table 2. The characteristic value of the 
compressive strength was computed by means of Equation (1) where $\sigma$ is the coefficient of variation and $f_{c m}$ the mean compressive strength obtained in the tests. No major changes were noticed in the modulus of elasticity of the SCC mixes. However, it would seem that the addition of fiber contents above $3 \mathrm{~kg} / \mathrm{m}^{3}$ might worsen the compaction of the concrete in the molds and thus reduce the test results. A similar phenomenon might also take place in the VCC mixes. When the values of $f_{c k}$ and $f_{c t}$ were analyzed, no variations in the values obtained out of the boundaries of the typical experimental scatter were noted.

$$
f_{c k}=f_{c m}-1.64 \sigma
$$

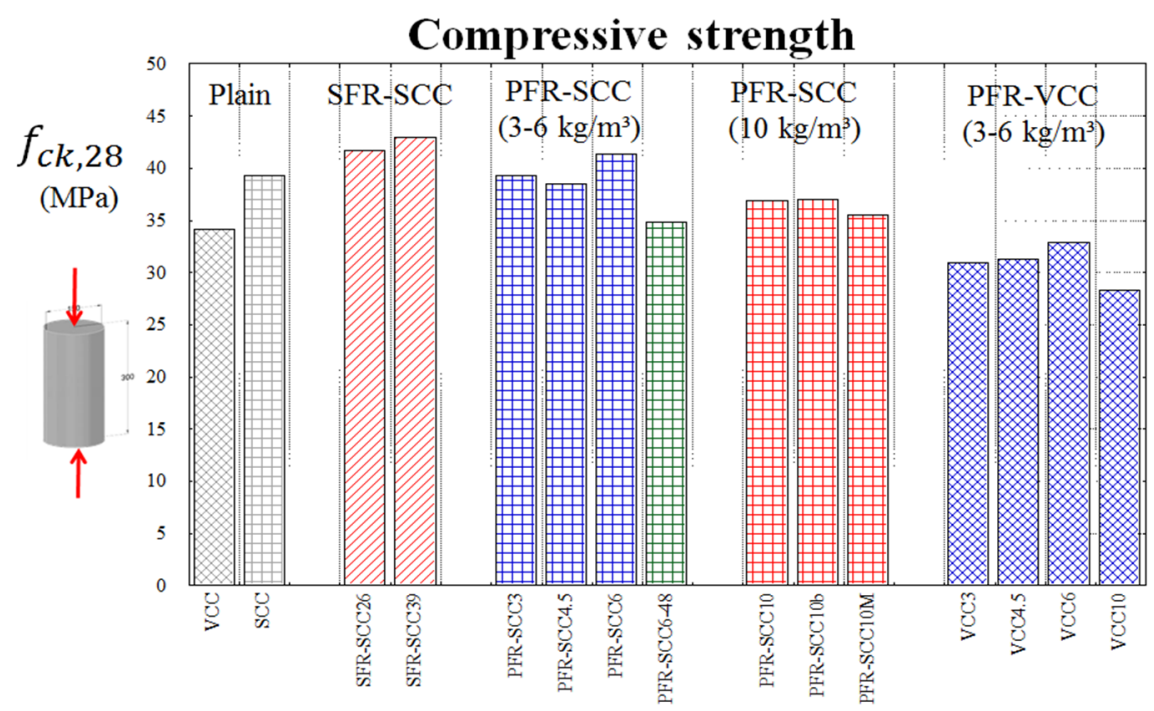

Figure 5. Compressive strength.

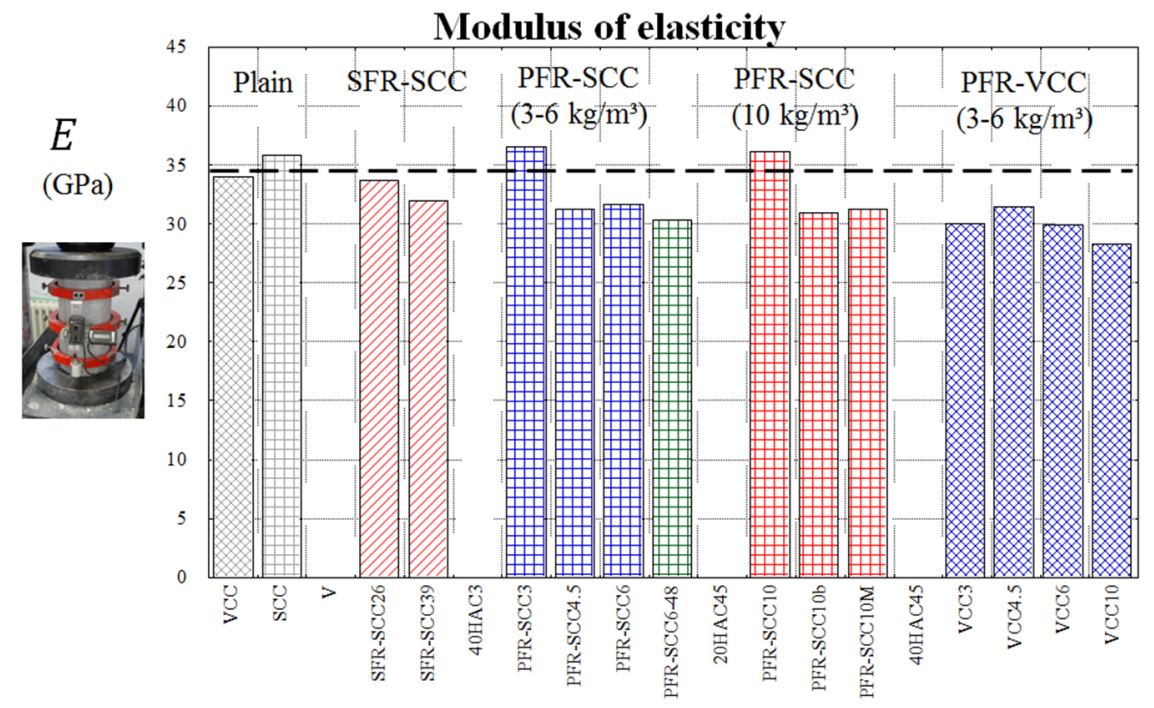

Figure 6. Modulus of elasticity. 


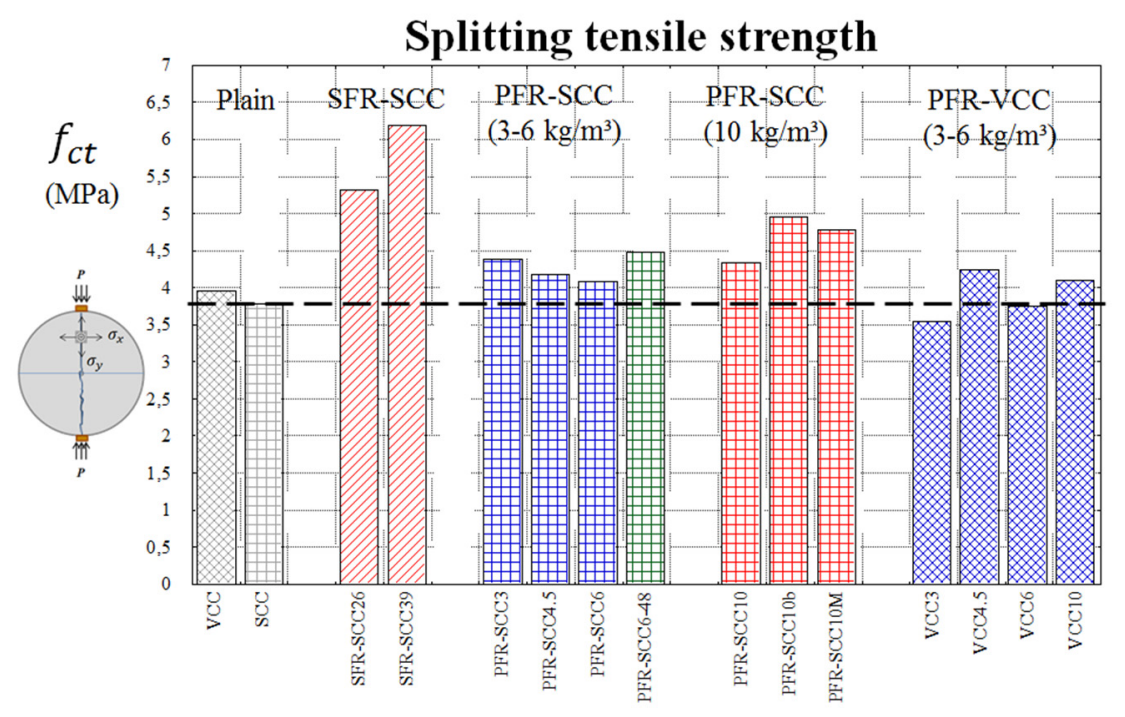

Figure 7. Splitting tensile strength.

Table 2. Mechanical properties of the polyolefin fiber-reinforced concrete (PFRC).

\begin{tabular}{ccccccc}
\hline Mixture & $\boldsymbol{f}_{\boldsymbol{c k}}(\mathbf{M P a})$ & $\mathbf{c . v}$. & $\boldsymbol{f}_{\boldsymbol{c t}}(\mathbf{M P a})$ & $\mathbf{c . v}$. & $\boldsymbol{E}(\mathbf{G P a})$ & c.v. \\
\hline VCC & 34 & 0.04 & 3.9 & 0.10 & 34 & 0.04 \\
SCC & 39 & 0.01 & 3.8 & 0.14 & 36 & 0.03 \\
VCC3 & 31 & 0.02 & 3.6 & 0.03 & 30 & 0.03 \\
SCC3 & 39 & 0.01 & 4.4 & 0.09 & 36 & 0.06 \\
VCC4.5 & 31 & 0.07 & 4.2 & 0.12 & 31 & 0.07 \\
SCC4.5 & 38 & 0.06 & 4.2 & 0.20 & 32 & 0.01 \\
VCC6 & 33 & 0.04 & 3.9 & 0.07 & 30 & 0.06 \\
SCC6 & 41.4 & 0.01 & 4.1 & 0.03 & 32 & 0.02 \\
SCC6-48 $*$ & 34.8 & 0.05 & 4.5 & 0.08 & 30 & 0.01 \\
VCC10 & 28 & 0.03 & 4.1 & 0.06 & 28 & 0.04 \\
SCC10 & 37 & 0.02 & 4.6 & 0.09 & 30 & 0.02 \\
\hline
\end{tabular}

Notes: * PFRC using $48 \mathrm{~mm}$-long polyolefin fibers. The rest of the PFRC formulations contain $60 \mathrm{~mm}$-long polyolefin fibers.

The durability performance was assessed by means of permeability tests according to the standard [30], with the results being shown in Figure 8. According to those obtained, the presence of fibers did not influence the connected porosity network of concrete. The value of the penetration of water under the pressure of all of the VCC mixes was greater than the equivalent formulation of SCC in all of the mixes. Therefore, it could be argued that the coarser aggregate skeleton of the VCC mixes is responsible for the more permeable pore structure. In addition, due to the limited depth of penetration, below $20 \mathrm{~mm}$, all the mixes made with SCC were suitable for use in extremely harmful environments in accordance with EHE-08 [8]. In contrast, VCC mixes (with depths of penetration below $30 \mathrm{~mm}$ ) were apt for use in medium-hazardous environments (according to EHE-08) due to a more permeable porous structure. Subsequently, it was concluded that the presence of the fibers had hardly any influence on the VCC and SCC results. 


\section{Depth of penetration of water under pressure (mm)}

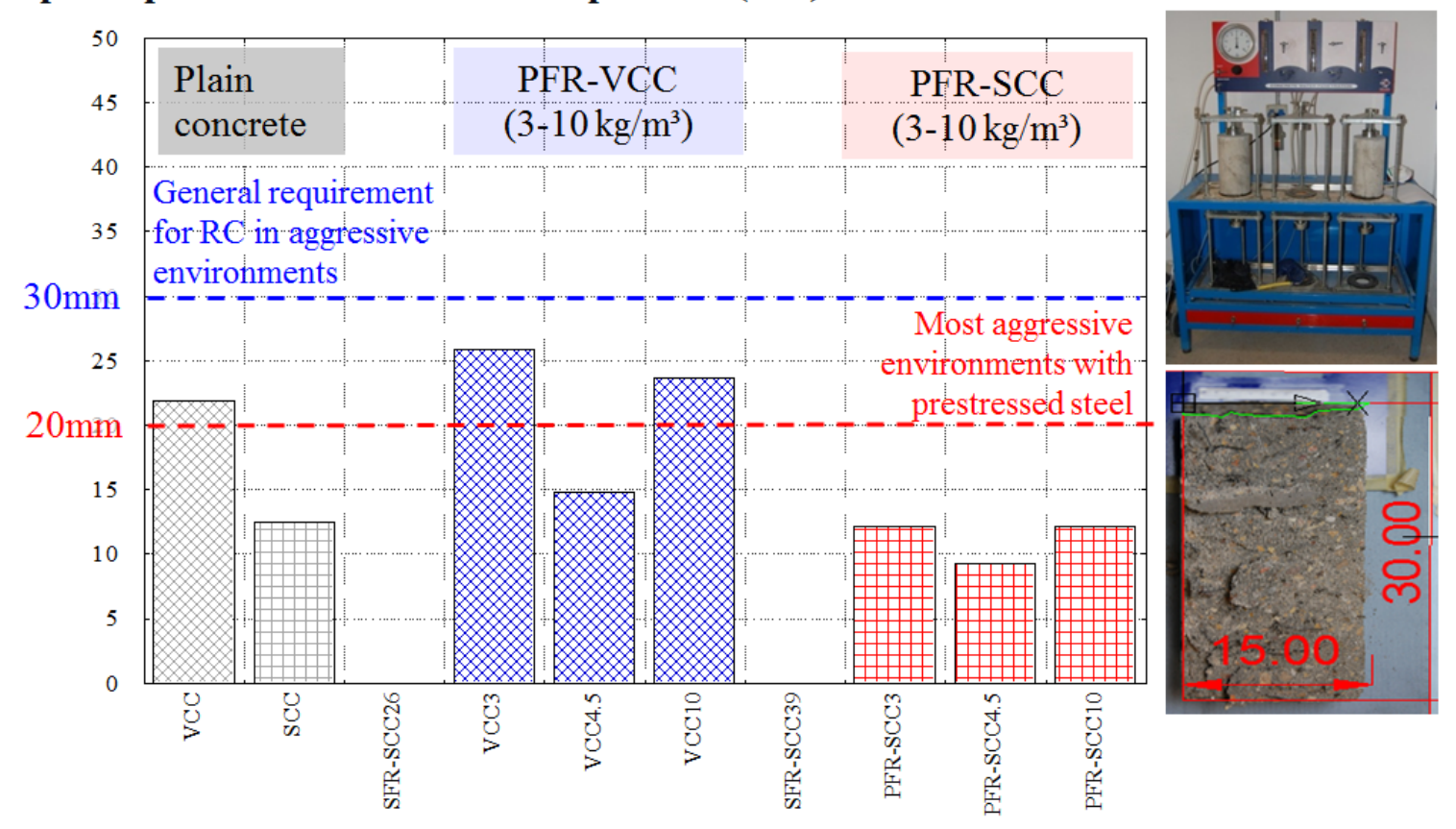

Figure 8. Depth of penetration under water pressure (mm).

\section{Assessment of Residual Strength: The Fracture Properties}

The fracture properties state the structural character of the fibers. In such a case, the residual strengths obtained from fracture tests are the values to be used in the structural design. As mentioned in the introduction, one of the reasons that motivated this study was the lack of research focused on the fracture properties of PFRC and the subsequent comparison with SFRC. However, the post-cracking properties are vital in providing an alternative to conventional bar reinforcement and steel fibers. Therefore, this section provides significant results that help to fill this gap. Such results showed that polyolefin fibers provide structural capacities to concrete and, hence, that the contributions of the fibers can be considered to reduce other reinforcements with reduced costs and the already mentioned environmental and durability benefits.

The substitution of steel bar by steel fibers is widely accepted and the tests carried out to design SFRC elements can also be used to characterize the fracture behavior of PFRC. These are EN 14651 [11], RILEM TC 162-TDF [10], ASTM C 1609/C 1690M-07 [12] and RILEM TC 187 SOC [31]. The test configurations described in such standards are depicted in Figure 9.

Recent research $[16,22,32]$ has shown that the PFRC provides fracture curves such as those shown in Figure 10. That is to say, three main turning points can define the behavior: the load at the limit of proportionality $\left(L_{L O P}\right)$, the minimum post-cracking load $\left(L_{M I N}\right)$ and the maximum post-cracking load-bearing capacity ( $\left.L_{R E M}\right)$. There is a slight influence of the polyolefin fibers on the values of load reached in the limit of proportionality. However, in the post-cracking region, the values of load are mainly governed by the presence of fibers. The residual load values can be transformed into strength values using Equation (2), assuming the classical strength of materials formulae and, therefore, allowing the use of such strengths in the structural design as recommended in the regulations $[7,8,11]$. In the 
expression, $f_{R, j}$ stands for strength, $F_{R, j}$ for the load, $L$ for the span, $b$ for the depth of the beam and $h_{s p}$ for the ligament length (see Figure 9).

$$
f_{R, j}=\frac{3}{2} \frac{F_{R, j} \cdot L}{b \cdot h_{s p}{ }^{2}}
$$
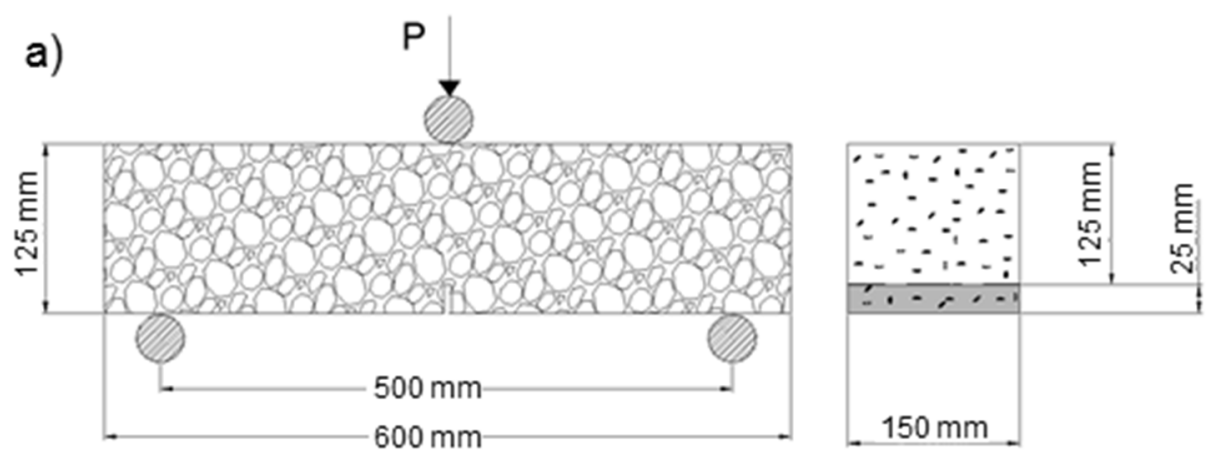

b)
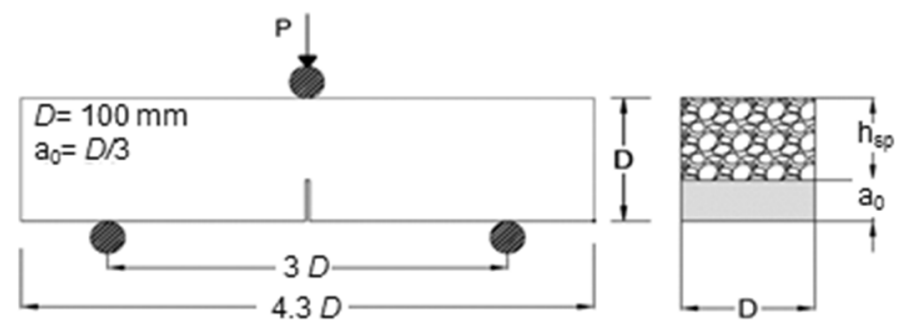

Figure 9. Configuration of the fracture tests: (a) EN 14651 and RILEM TC 162-TDF; (b) RILEM TC 187 SOC and ASTM C 1609/C 1690M-07.

Fracture behavior of PFRC

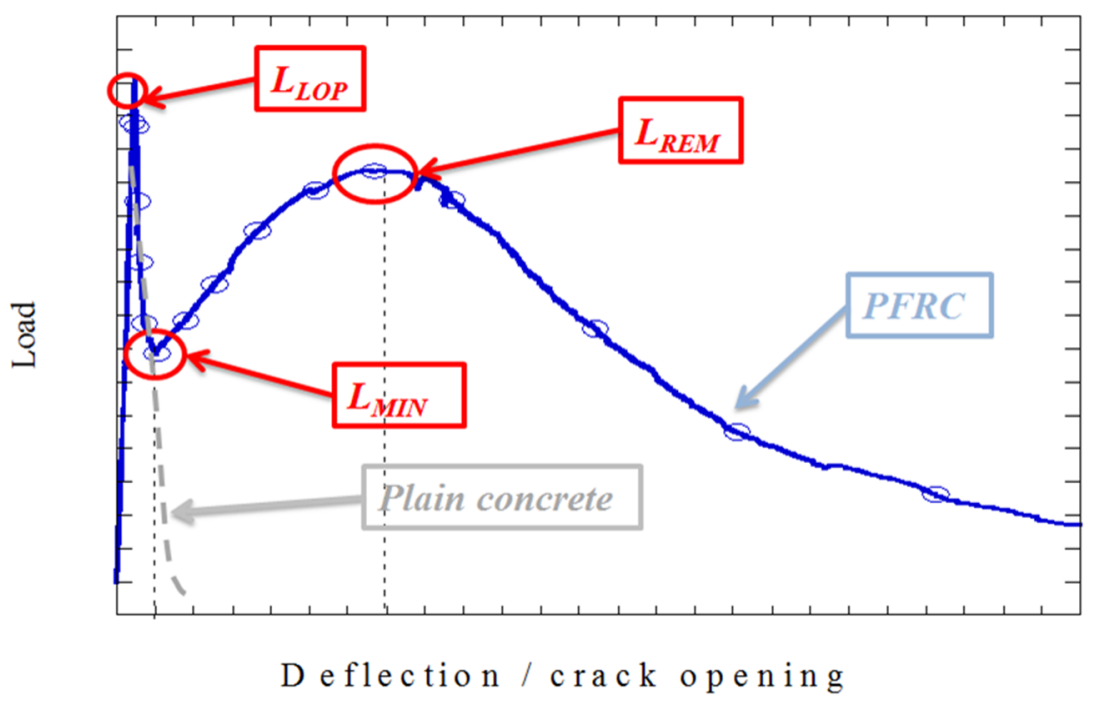

Figure 10. Sketch of the typical fracture curve of PFRC.

The results of Reference [16] showed that the best performance of PFRC occurred for larger deformations than those analogues of SFRC. For the initial crack openings, steel-hooked fibers lessen the fall of strength once the limit of proportionality is surpassed. Figure 11a shows the mean results of three specimens of each type of PFRC with dosages ranging from 3 to $10 \mathrm{~kg} / \mathrm{m}^{3}$. Figure $11 \mathrm{~b}$ shows the 
results of SFR-SCC with, respectively, 26 and $39 \mathrm{~kg} / \mathrm{m}^{3}$ of steel-hooked fibers. The higher elasticity modulus and the mechanical anchorage of the hooks improve the behavior in the very first crack openings.
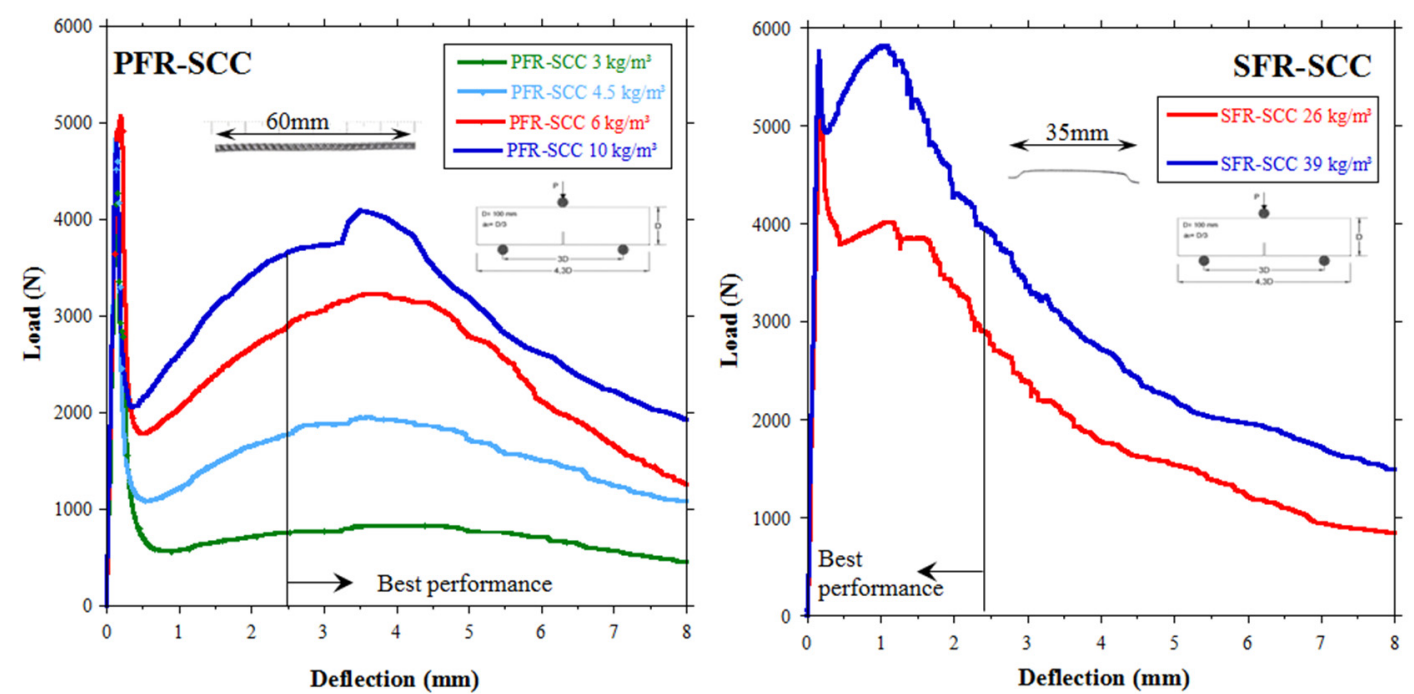

Figure 11. Fracture results using the same mix proportioning of SCC: (a) PFR-SCC; (b) SFR-SCC.

The definition of a structural fiber type slightly varies from the EN 14889 [33] and Model Code [7] or EHE-08 [8]. For SLS, use of the value of strength of the FRC at a crack opening of $0.5 \mathrm{~mm}$ is accepted. For ULS, the value obtained at $2.5 \mathrm{~mm}$ of the crack opening is accepted. The values of strength at such a crack opening are commonly known, respectively, as $f_{R 1}$ and $f_{R 3}$ (see Figure 12). These strengths could be assumed as the contribution of the fibers in the structural design if some additional requirements are met.

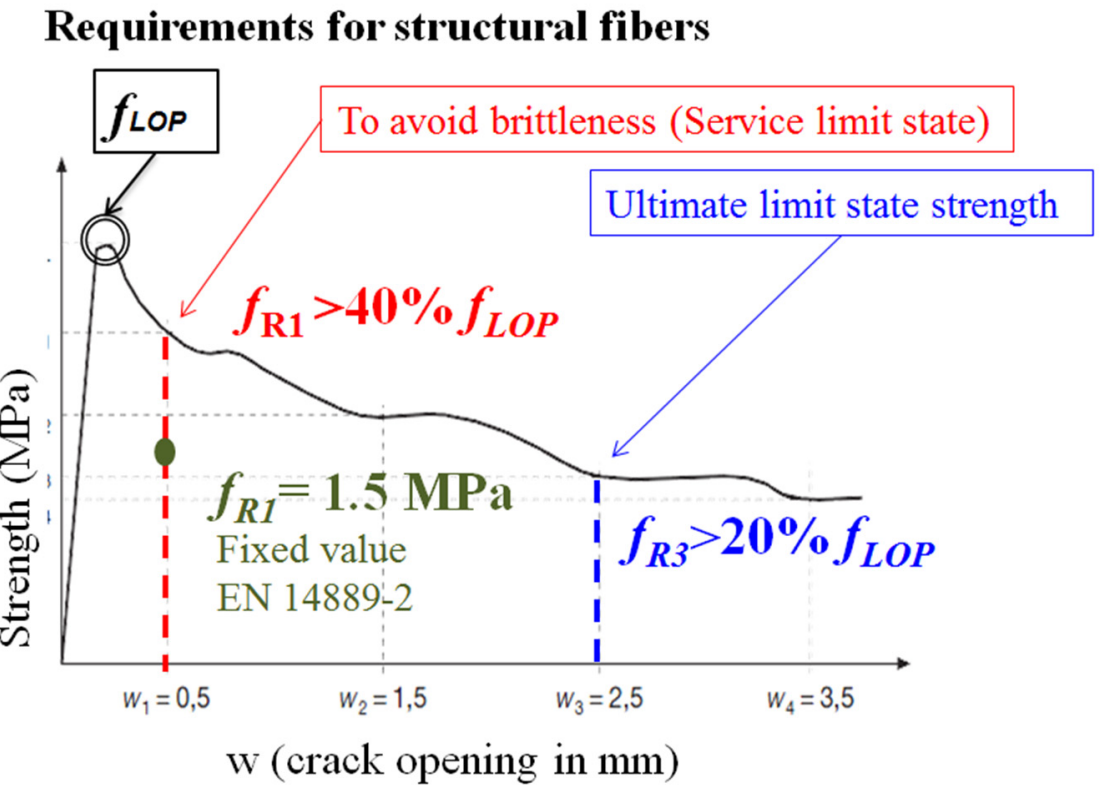

Figure 12. Requirements of the standards to consider the contribution of the fibers in the structural design. 
The Model Code states that fiber reinforcement can substitute (also partially) conventional reinforcement at ultimate limit state if the relationships of Equation (3) and Equation (4) are fulfilled:

$$
\begin{aligned}
& \frac{f_{R 1}}{f_{L O P}}>0.40 \\
& \frac{f_{R 1}}{f_{R 3}}>0.50
\end{aligned}
$$

These requirements in terms of a proportion of $f_{\text {lop }}$ contrast with the minimum fixed value of $1.5 \mathrm{MPa}$ proposed by EN 14889-2 for $f_{R}$. Establishing a proportional value permits brittleness to be avoided, although it induces a dependence on the tensile strength of concrete. These issues remain of concern for any future review of the regulations, though, at the time of writing, regulations [7,8] differentiate between structural and non-structural use of fibers.

The results of $f_{R 1}$ and $f_{R 3}$ and the strength at the crack opening $3.5 \mathrm{~mm}\left(f_{R 4}\right)$ obtained as the average of two specimens of size $600 \times 150 \times 150 \mathrm{~mm}^{3}$ are shown in Table 3. Additionally, the percentage with respect to $f_{L O P}$ has also been computed. By analyzing the table it can be concluded that the dosage reaching structural values in $f_{R}$, close to $1.5 \mathrm{MPa}$, is $6 \mathrm{~kg} / \mathrm{m}^{3}$. The dosage of $10 \mathrm{~kg} / \mathrm{m}^{3}$ fully complies with the standards and shows improvements when using SCC. It should be noted that all the strengths $f_{R 4}$ were higher than $f_{R 3}$, showing that taking the value of $f_{R 3}$ does not obtain all the possible benefits of the fibers. Moreover, it should be highlighted that all dosages of polyolefin fibers, even those in the lower threshold of the use of such plastic fibers $\left(3 \mathrm{~kg} / \mathrm{m}^{3}\right)$, exceeded the values required by the standards of being greater than $20 \%$ of $f_{L O P}$ at $f_{R 3}$. Besides, in order to reach $f_{R I}$ strengths higher than $40 \%$ of $f_{L O P}$, $48 \mathrm{~mm}$-long fibers showed a better behavior compared with the longer fibers.

Table 3. Residual strengths obtained from flexural tensile strength tests [19,22] following EN 14651 [11].

\begin{tabular}{cccccccc}
\hline $\begin{array}{c}\text { Residual Strength } \\
\text { (MPa) (c.v.) }\end{array}$ & $\boldsymbol{f}_{\boldsymbol{L} O \boldsymbol{O P}}$ & $\boldsymbol{f}_{\boldsymbol{R} \boldsymbol{I}}$ & $\boldsymbol{\%} \boldsymbol{f}_{\boldsymbol{L} \boldsymbol{O} \boldsymbol{P}}$ & $\boldsymbol{f}_{\boldsymbol{R} 3}$ & $\boldsymbol{\%} \boldsymbol{f}_{\boldsymbol{L} \boldsymbol{O P}}$ & $\boldsymbol{f}_{\boldsymbol{R} 4}$ & $\boldsymbol{\%} \boldsymbol{f}_{\boldsymbol{L} O \boldsymbol{P}}$ \\
\hline VCC3 & $4.81(0.15)$ & $0.93(0.30)$ & $19 \%$ & $0.96(0.22)$ & $20 \%$ & $0.97(0.20)$ & $21 \%$ \\
SCC3 & $5.21(0.04)$ & $0.93(0.01)$ & $18 \%$ & $1.15(0.01)$ & $22 \%$ & $1.27(0.04)$ & $26 \%$ \\
VCC4.5 & $4.74(0.04)$ & $1.06(0.06)$ & $22 \%$ & $1.40(0.06)$ & $29 \%$ & $1.56(0.06)$ & $33 \%$ \\
SCC4.5 & $5.23(0.08)$ & $0.95(0.07)$ & $18 \%$ & $1.25(0.05)$ & $24 \%$ & $1.32(0.02)$ & $25 \%$ \\
VCC6 & $4.41(0.00)$ & $1.57(0.03)$ & $36 \%$ & $2.38(0.06)$ & $54 \%$ & $2.61(0.07)$ & $59 \%$ \\
SCC6 & $5.09(0.00)$ & $1.39(0.09)$ & $27 \%$ & $2.03(0.16)$ & $40 \%$ & $2.25(0.12)$ & $44 \%$ \\
SCC6-48 $*$ & $4.57(0.24)$ & $1.50(0.26)$ & $33 \%$ & $2.21(0.28)$ & $48 \%$ & $2.24(0.32)$ & $49 \%$ \\
VCC10 & $4.21(0.14)$ & $1.98(0.15)$ & $47 \%$ & $2.87(0.11)$ & $68 \%$ & $3.05(0.11)$ & $72 \%$ \\
SCC10 & $5.22(0.05)$ & $2.41(0.04)$ & $46 \%$ & $3.87(0.03)$ & $74 \%$ & $4.16(0.03)$ & $80 \%$ \\
\hline
\end{tabular}

Notes: * PFRC using $48 \mathrm{~mm}$-long polyolefin fibers. The rest of the PFRC formulations contain $60 \mathrm{~mm}$-long polyolefin fibers.

\section{Designing a Combination of Steel Fibers with Polyolefin Fibers}

Figure 13 provides a comparison of the shapes of the PFRC and SFRC curves and justifies the combination of the two types of fibers. As can be seen in the figure, SFRC showed a scattered fall of strength typical of the rectification of the hooks, and the PFRC revealed a remarkable performance of 
the polyolefin fibers in advanced deformations. Since the weak point of the use of PFRC occurs for small deformations, the question appeared as a hypothesis: would it be possible to produce a FRC-SCC by using both types of fibers with a stable post-cracking response close to the value in limit of proportionality?

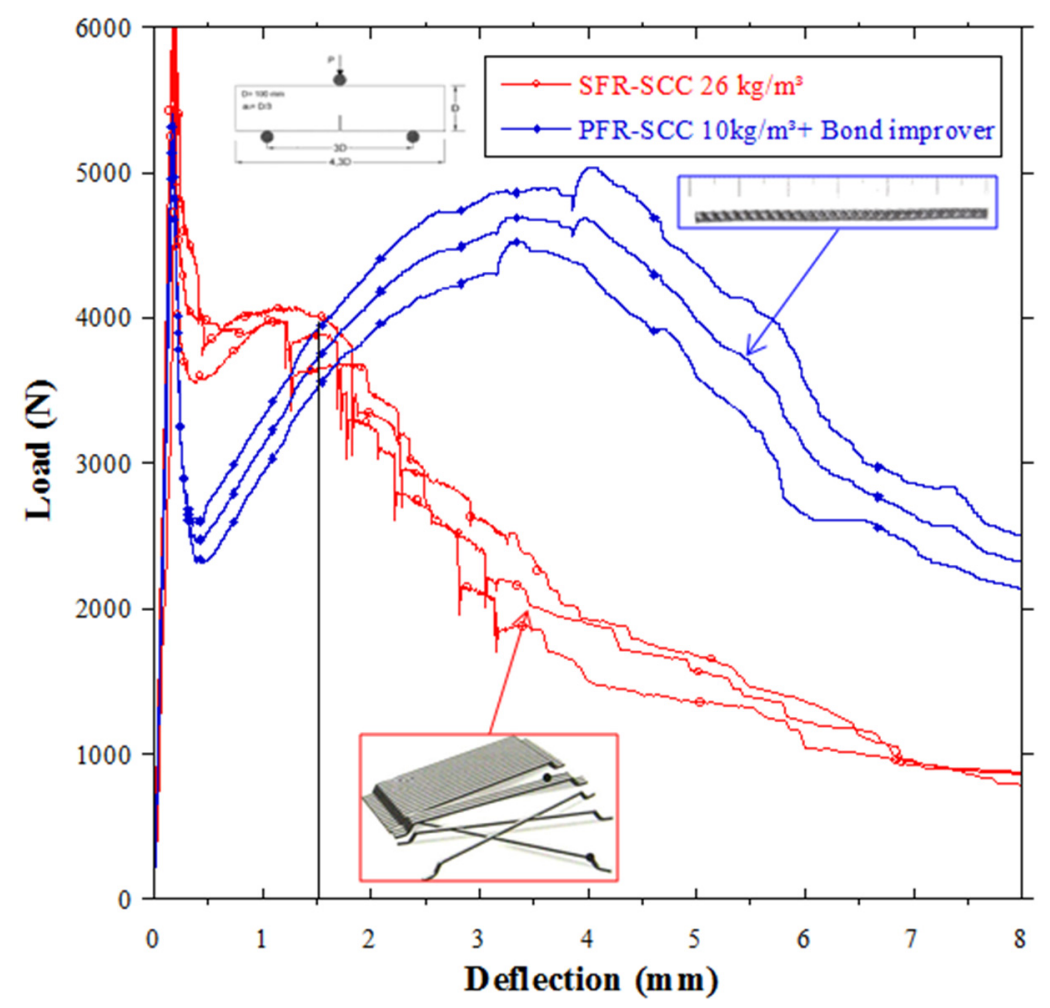

Figure 13. Results using an admixture designed to improve the adherence between the polyolefin fiber and the matrix.

In order to respond to this, two dosages previously studied should be chosen as a reference. On the one hand, as the sum of the volume fractions was desired to be around $1 \%$, the lower dosage of SF $(0.33 \%)$ and an intermediate of PF (PFR-SCC4.5 means $0.49 \%$ in volume) seemed to be adequate. On the other, short steel-hooked fibers would allow the response for the small crack opening to be raised, which would mean that the best combination would be the $60 \mathrm{~mm}$-long polyolefin fibers. Thus, the hybrid mixture named as $\mathrm{H} 1$ was defined, and the same specimens used for the previous types of concrete were produced in two batches. The mixing sequence was redefined as shown in Figure 14. At this point, it is worth mentioning that $60 \mathrm{~mm}$-long polyolefin fibers have 27,000 fibers per $\mathrm{kg}$, while the $35 \mathrm{~mm}$-long steel-hooked fibers have 14,500. If the fibers were perfectly aligned with the stress direction of the bending tests, the theoretical number of fibers (th) appearing on a fracture surface of each dosage could be shown. This has been carried out and is included in Table 4.

Table 4 shows the results of the fresh-state and mechanical testing campaign. As can be seen, the use of the hybrid mixture did not affect the fresh state more than the steel fibers did. Furthermore, the results with a volume fraction of $0.82 \%$ showed that the mixture kept the self-compacting character. The changes in the hardened state were unnoticeable in compressive strength and elasticity modulus. However, the indirect tensile strength tests showed that the combination of fibers improved the results. It should be noted that this test is inappropriate for FRC, as second-order effects impede an apposite analysis of the results (see [19]). 


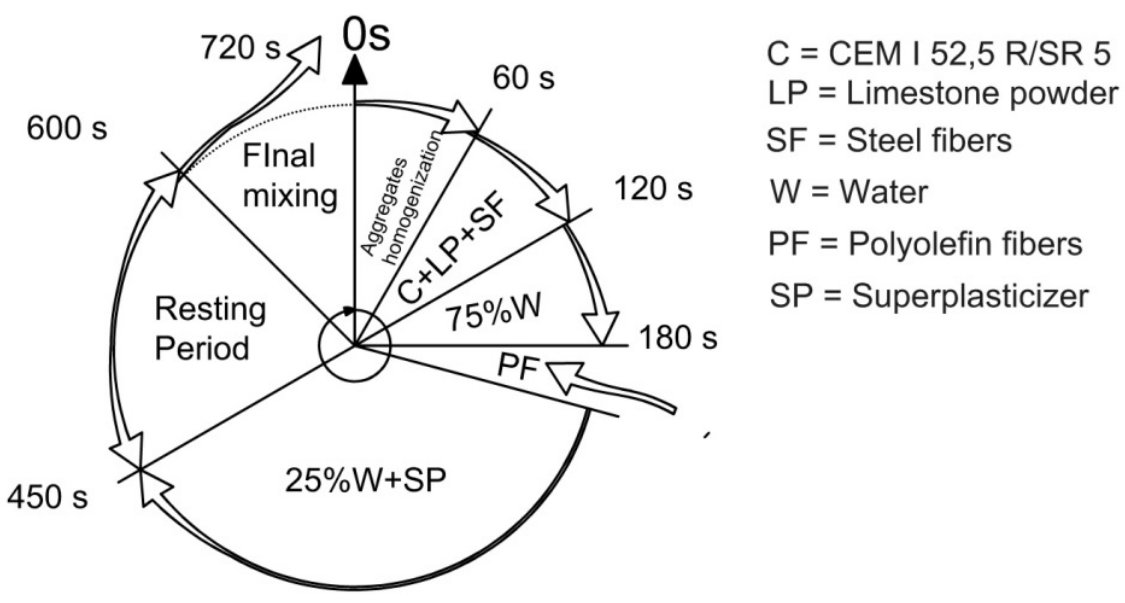

Figure 14. Mixing sequence.

Table 4. Fresh-state results and mechanical properties of the mixture H1.

\begin{tabular}{|c|c|c|c|c|c|c|}
\hline State & \multicolumn{2}{|c|}{ Test } & SCC & S26 & P4.5 & H1 \\
\hline \multirow{3}{*}{$\begin{array}{c}\text { Fresh } \\
\text { state }\end{array}$} & \multirow{2}{*}{$\begin{array}{c}\text { Slump flow } \\
\text { test }\end{array}$} & $T_{500}(\mathrm{~s})$ & 3.5 & 3.5 & 3.5 & 4 \\
\hline & & $d_{f}(\mathrm{~mm})$ & 655 & 570 & 600 & 565 \\
\hline & \multicolumn{2}{|c|}{ V-funnel $T_{V}(\mathrm{~s})$} & 8 & 14 & 11 & 14 \\
\hline & \multicolumn{2}{|c|}{$V_{f}(\%)$} & & 0.33 & 0.49 & 0.82 \\
\hline & \multicolumn{2}{|c|}{ th (number) } & & 139 & 74 & $139+74$ \\
\hline & \multicolumn{2}{|c|}{ Elasticity Modulus (GPa) } & 35.8 & 33.7 & 31.2 & 33 \\
\hline Hardened & \multicolumn{2}{|c|}{ c.v. } & 0.03 & 0.01 & 0.01 & 0.03 \\
\hline state & \multicolumn{2}{|c|}{$f_{c k}, 28$ days $(\mathrm{MPa})$} & 39 & 41.7 & 38.5 & 36.5 \\
\hline & \multicolumn{2}{|c|}{ c.v. } & 0.01 & 0.01 & 0.06 & 0.03 \\
\hline & \multicolumn{2}{|c|}{$f_{c t}$ indirect $(\mathrm{MPa})$} & 3.8 & 5.3 & 4.2 & 5.41 \\
\hline & \multicolumn{2}{|c|}{ c.v. } & 0.14 & 0.15 & 0.20 & 0.04 \\
\hline
\end{tabular}

The fracture curves are shown in Figure 15 and provide an improved analysis of the residual capacities of the hybrid mixture H1. In the figure, it can be observed that the hybrid mixture H1 obtained a higher residual load-bearing capacity than an algebraic sum of the post-cracking curves of the mono-fiber mixtures (SFR-SCC26 + PFR-SCC4.5). This showed that synergies emerged in the combined use of the two types of fibers. In addition, if Table 5 is observed, the residual strengths were higher than $90 \%$ of $f_{L O P}$. The analysis in terms of fracture energy (see also Table 5) obtained at a deflection of $8 \mathrm{~mm}$ provides a $10 \%$ increase when compared with the algebraic sum of the fracture energies of SFR-SCC26 and PFR-SCC4.5.

Table 5. Residual strengths of H1.

\begin{tabular}{ccccccc}
\hline $\begin{array}{c}\text { Residual Strength } \\
(\mathbf{M P a})(\mathbf{c . v .})\end{array}$ & $\boldsymbol{f}_{\boldsymbol{L} \boldsymbol{O P} \boldsymbol{P}}(\mathbf{M P a})$ & $\boldsymbol{f}_{\boldsymbol{R} \boldsymbol{I}}(\mathbf{M P a})$ & $\boldsymbol{\%}$ & $\boldsymbol{f}_{\boldsymbol{R} \boldsymbol{3}}(\mathbf{M P a})$ & $\boldsymbol{\%}$ & $\boldsymbol{G}_{\boldsymbol{F}}(\mathbf{N} / \mathbf{m})$ \\
\hline SCC & $5.03(0.04)$ & - & - & - & - & $130(0.05)$ \\
SFR-SCC26 & $6.05(0.06)$ & $3.81(0.05)$ & $63 \%$ & $3.45(0.06)$ & $57 \%$ & $2621(0.05)$ \\
PFR-SCC4.5 & $5.73(0.01)$ & $1.15(0.20)$ & $20 \%$ & $1.66(0.28)$ & $29 \%$ & $1846(0.42)$ \\
H1 & 5.48 & $4.95(0.08)$ & $90 \%$ & $5.36(0.07)$ & $98 \%$ & $4931(0.12)$ \\
\hline
\end{tabular}




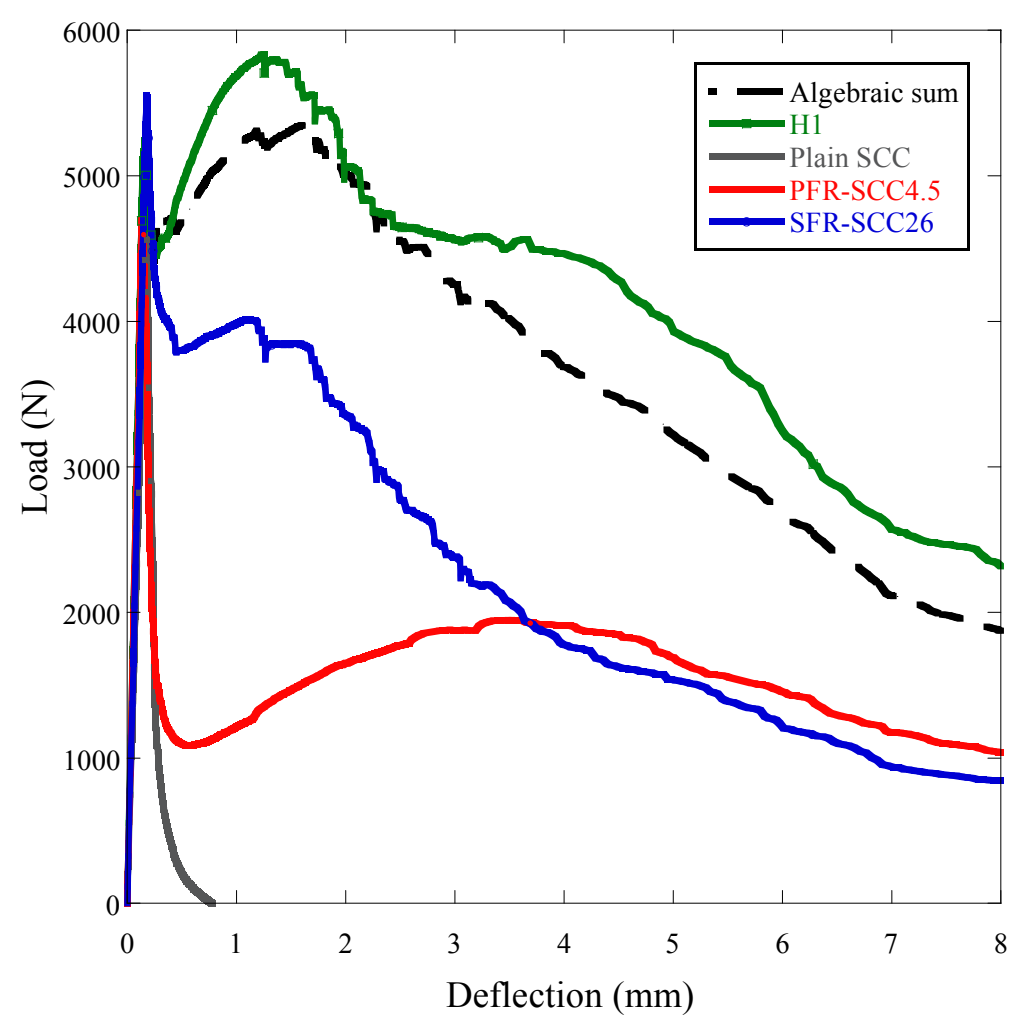

Figure 15. Fracture results of $\mathrm{H} 1$ and the sum of the residual contributions of mono-fiber reinforced mixtures.

The fracture surface analysis showed that the combination of the two types of fibers produced an increase in the orientation factor of both types of fibers, as can be seen in Table 6 . The description of the procedure to obtain $\theta$ and its definition can be studied in more detailed in References [19,32].

Table 6. Orientation factor.

\begin{tabular}{ccc}
\hline \multirow{2}{*}{ Mixture } & \multicolumn{2}{c}{$\boldsymbol{\theta}$ (Orientation factor) } \\
\cline { 2 - 3 } & SF & PF \\
\hline SFR-SCC26 & 0.68 & - \\
PFR-SCC4.5 & - & 0.61 \\
H1 & 0.75 & 0.63 \\
\hline
\end{tabular}

\section{Summary of Conclusions}

This study has shown that polyolefin fiber reinforced concrete (PFRC) is well-suited for its use in infrastructure applications such as in the construction of pavements, light precast elements, tunnel linings and water pipelines. Additionally, it provides values of the residual contributions of such macro-synthetic fibers for the structural designer. Given the difficulty in reaching the values required for small deformations, it could offer promising lines of research — such as the combination of two types of fibers - for future works in FRC to consider. The simultaneous use of short steel-hooked fibers and longer polyolefin ones is particularly well-suited for structural applications. The conclusions derived from this work can be summarized as follows: 
- Polyolefin fibers showed very good performance in fresh state-especially adequate for use when self-compacting properties are required.

- The compressive strength and modulus of elasticity of PFRC remain at similar values to those of plain concrete, while tensile strength increases due to the presence of fibers. The increases in the indirect tensile strength were observed, though the percentage increase using PFRC were limited in comparison with the results obtained through the use of steel-hooked fibers to reinforce the same mix proportioning of concrete.

- PFRC shows significant improvements in toughness and ductility. The presence of fibers allow deformations beyond the conventional considered in civil engineering structures. The fracture energy $\left(G_{F}\right)$ with $4.5 \mathrm{~kg} / \mathrm{m}^{3}$ of polyolefin increased by 14.2 . With the use of steel-hooked fibers in a dosage of $26 \mathrm{~kg} / \mathrm{m}^{3}$, the fracture energy was 20 times that of plain concrete. The combination of the two types of fibers was 38 times $G_{F}$ of the plain concrete, showing synergy effects a $10 \%$ increment of $G_{F}$.

- The residual load-bearing capacity of PFRC has shown its best performance for crack openings in the range of 1 to $5 \mathrm{~mm}$. The requirements of the standards at crack openings of $2.5 \mathrm{~mm}, f_{R 3}$, were met even for the mixture with fewer amounts of fibers $\left(3 \mathrm{~kg} / \mathrm{m}^{3}\right)$.

- The residual strengths at initial crack opening were shown to be the lowest residual value and the weakest point of PFRC. In order to consider the structural contribution of fibers at such deformations, and therefore surpass the strength of $1.5 \mathrm{MPa}$, the limit dosage was found to be around $6 \mathrm{~kg} / \mathrm{m}^{3}$.

- The combination of polyolefin fibers with a small amount of short steel-hooked fibers were shown to offer a good solution in improving the residual values for small deformations. Additionally, the simultaneous use of the two types of fibers produce a synergistic effect which provides an efficient use of the materials, as well as a better mechanical behavior in both service and failure states.

\section{Acknowledgments}

The authors gratefully acknowledge the financial support provided by the Ministry of Economy and Competitiveness of Spain by means of the Research Fund Project DPI 2011-24876. They also offer their gratitude to SIKA SAU for supporting the Enterprise University Chair, the Cátedra Sika-UPM.

\section{Author Contribution}

The current paper reports a combination of efforts made by the three authors. In order to attribute some individual merits, the following words can express the research methodology in which any of them could be equally mentioned. Marcos G. Alberti carried out the design and production of the concrete and performed the experimental campaign presented in this manuscript within the frame of his Doctoral dissertation. Together with him, Alejandro Enfedaque and Jaime C. Gálvez developed the analysis and discussion as supervisors of all of the technical work reported. Jaime C. Gálvez was the initiator of the research idea as the Head Researcher of the Enterprise University Chair, the Cátedra Sika-UPM. 


\section{Conflicts of Interest}

The authors declare no conflict of interest.

\section{Acronyms}

\begin{tabular}{ll}
\hline Acronym & Definition \\
\hline FRC & Fiber-reinforced concrete \\
FR-SCC & Fiber-reinforced self-compacting concrete \\
LP & Limestone powder \\
PF & Polyolefin fiber \\
PFR-SCC & Polyolefin fiber-reinforced self-compacting concrete \\
PFRC & Polyolefin fiber-reinforced concrete \\
RC & Steel-bar Reinforced Concrete \\
SCC & Self-compacting concrete \\
SF & Steel fiber \\
SFR-SCC & Steel fiber-reinforced self-compacting concrete \\
SFRC & Steel fiber-reinforced concrete \\
SLS & Service limit state \\
SP & Superplasticizer \\
ULS & Ultimate limit state \\
VCC & Vibrated conventional concrete \\
\hline
\end{tabular}

\section{References}

1. Jeon, J.K.; Kim, W.; Jeon, C.K.; Kim, J.C. Processing and Mechanical Properties of Macro Polyamide Fiber Reinforced Concrete. Materials 2014, 7, 7634-7652.

2. Chung, D. Multifunctional Cement-Based Materials; Marcel Dekker Inc.: New York, NY, USA, 2003.

3. Zollo, R. Fiber-reinforced concrete: An overview after 30 years of development. Cem. Concr. Compos. 1997, 19, 107-122.

4. Cavalaro, S.H.P.; López, R.; Torrents, J.M.; Aguado, A. Improved assessment of fiber content and orientation with inductive method in SFRC. Mater. Struct. 2015, 48, 1859-1873.

5. Serna, P.; Arango, S.; Ribeiro, T.; Núñez, A.M.; Garcia-Taengua, E. Structural cast-in-place SFRC: Technology, control criteria and recent applications in spain. Mater. Struct. 2009, 42, 1233-1246.

6. American Concrete Institute (ACI). Guide for Specifying, Proportioning, and Production of Fiber Reinforced Concrete; ACI Committee 544. ACI 544.3R-08; American Concrete Institute: Farmington Hills, MI, USA, 2008.

7. International Federation for Structural Concrete (fib). The fib Model Code for Concrete Structures 2010; International Federation for Structural Concrete: Lausanne, Switzerland, 2010.

8. Spanish Minister of Public Works. Spanish Structural Concrete Code EHE-08; Spanish Minister of Public Works: Madrid, Spain, 2008. 
9. Consiglio Nazionale delle Riserche. Guide for the Design and Construction of Fiber-Reinforced Concrete Structures; CNR-DT 204; Consiglio Nazionale delle Riserche: Roma, Italy, 2006.

10. International Union of Laboratories and Experts in Constructiuon Materials, Systems and Structures (RILEM). Bending Test: Final Recommendations; RILEM TC-162-TDF; RILEM: Bagneux, France, 2002.

11. European Committee for Standardization (CEN). Test Method for Metallic Fiber Concrete. Measuring the Flexural Tensile Strength (Limit of Proportionality (LOP), Residual; EN 14651:2005+A1; CEN: Bruxelles, Belgium, 2007.

12. American Society for Testing and Materials (ASTM). Standard Test Method for Flexural Performance of Fiber Reinforced Concrete (Using Beam with Third-Point Loading); ASTM C 1609/C 1690M-07; ASTM: West Conshohocken, PA, USA, 2007; pp. 1-8.

13. Yu, R.; Spiesz, P.; Brouwers, H.J.H. Development of Ultra-High Performance Fiber Reinforced Concrete (UHPFRC): Towards an Efficient Utilization of Binders and Fibers. Constr. Build. Mater. 2015, 79, 273-282.

14. Ramakrinshnan, V. Structural Application of Polyolefin Fiber Reinforced Concrete. ACI 1999, 183, 235-253.

15. Ugbolue, S.C. Polyolefin Fibers: Industrial and Medical Applications; CRC Press: Cambridge, UK, 2009.

16. Alberti, M.G.; Enfedaque, A.; Gálvez, J.C. On the mechanical properties and fracture behavior of polyolefin fiber-reinforced self-compacting concrete. Constr. Build. Mater. 2014, 55, 274-288.

17. Yin, S.; Tuladhar, R.S.F.; Combe, M.; Collister, T.; Sivakugan, N. Use of macro plastic fibers in concrete: A review. Constr. Build. Mater. 2015, 93, 180-188.

18. Wimpenny, D.; Angerer, W.; Cooper, T.; Bernard, S. The Use of Steel and Synthetic Fibers in Concrete under Extreme Conditions. In 24th Biennial Conference of the Concrete Institute of Australia, Sydney, Australia, 17 September 2009.

19. Alberti, M.G. Polyolefin Fiber-Reinforced Concrete: From Material Behavior to Numerical and Design Considerations. Ph.D. Thesis, Technical University Madrid, Madrid, Spain, 2015.

20. Soutsos, M.N.; Le, T.T.; Lampropoulos, A.P. Flexural performance of fiber reinforced concrete made with steel and synthetic fibers. Constr. Build. Mater. 2012, 36, 704-710.

21. Pujadas, P.; Blanco, A.; Cavalaro, S.H.P.; Aguado, A.; Grünewald, S.; Blom, K.; Walraven, J.C. Plastic fibers as the only reinforcement for flat suspended slabs: Parametric study and design considerations. Constr. Build. Mater. 2014, 70, 88-96.

22. Alberti, M.G.; Enfedaque, A.; Gálvez, J.C. Comparison between polyolefin fiber reinforced vibrated conventional concrete and self-compacting concrete. Constr. Build. Mater. 2015, 85, 182-194.

23. Behfarnia, K.; Behravan, A. Application of high performance polypropylene fibers in concrete lining of water tunnels. Mater. Des. 2014, 55, 274-279.

24. European Committee for Standardization (CEN). Testing Fresh Concrete. Part 8: Self-Compacting Concrete. Slump-Flow Test; EN 12350-8; CEN: Bruxelles, Belgium, 2010.

25. European Committee for Standardization (CEN). Testing Fresh Concrete. Part 9: Self-Compacting Concrete. V-Funnel Test; EN 12350-9; CEN: Bruxelles, Belgium, 2010. 
26. European Committee for Standardization (CEN). Testing Fresh Concrete. Part 2: Slump Test, European Committee for Standardization; EN 12350-2; CEN: Bruxelles, Belgium, 2002.

27. European Committee for Standardization (CEN). Testing Hardened Concrete. Part 3: Compressive Strength of Test Specimens; EN 12390-3; CEN: Bruxelles, Belgium, 2009.

28. European Committee for Standardization (CEN). Testing Hardened Concrete. Part 6. Tensile Spliting Strength of Test Specimens; EN 12390-6; CEN: Bruxelles, Belgium, 2009.

29. European Committee for Standardization (CEN). Testing Hardened Concrete. Part 13: Determination of Secant Modulus of Elasticity in Compression; EN 12390-13; CEN: Bruxelles, Belgium, 2013.

30. European Committee for Standardization (CEN). Testing Hardened Concrete. Depth of Penetration of Water under Pressure; EN 12390-8; CEN: Bruxelles, Belgium, 2000.

31. European Committee for Standardization (CEN). Indirect Test for Stress-Crack Opening Curve; RILEM TC-187-SOC; CEN: Bruxelles, Belgium, 2007.

32. Alberti, M.G.; Enfedaque, A.; Gálvez, J.C.; Cánovas, M.F.; Osorio, I.R. Polyolefin fiber-reinforced concrete enhanced with steel-hooked fibers in low proportions. Mater. Des. 2014, 60, 57-65.

33. European Committee for Standardization (CEN). Fibers for Concrete.Polymer Fibers. Definitions, Specifications and Conformity; EN 14889-2; CEN: Bruxelles, Belgium, 2008.

(C) 2015 by the authors; licensee MDPI, Basel, Switzerland. This article is an open access article distributed under the terms and conditions of the Creative Commons Attribution license (http://creativecommons.org/licenses/by/4.0/). 